\title{
Monitoring Heavy Metals near Wastewater Facility in Delaware Inland Bays Tidal Canal
}

\author{
Amy C. Cannon, Lathadevi K. Chintapenta, Gulnihal Ozbay* \\ Department of Agriculture and Natural Resources, Delaware State University, Dover, DE, USA \\ Email: *gozbay@desu.edu
}

How to cite this paper: Cannon, A.C., Chintapenta, L.K. and Ozbay, G. (2017) Monitoring Heavy Metals near Wastewater Facility in Delaware Inland Bays Tidal Canal. Journal of Water Resource and Protection, 9, 985-998.

https://doi.org/10.4236/jwarp.2017.98065

Received: April 9, 2017

Accepted: July 7, 2017

Published: July 10, 2017

Copyright () 2017 by authors and Scientific Research Publishing Inc. This work is licensed under the Creative Commons Attribution International License (CC BY 4.0).

http://creativecommons.org/licenses/by/4.0/

\begin{abstract}
NOAA National Status and Trends Mussel Watch Report indicate the Delaware Bay has regionally medium levels of $\mathrm{Cd}$ and high levels of $\mathrm{Pb}$. Environment New Jersey, a non-profit environmental group, reported the Delaware River, providing drinking water to millions, as the fifth most-polluted river in the country. These concerns resulted in this study monitoring water quality conditions near a wastewater facility in Delaware. Physical water quality parameters were measured, along with heavy metals $\mathrm{Cd}$ and $\mathrm{Pb}$. Mean metal levels were consistently low at the wastewater discharge $(1.3 \mu \mathrm{g} / \mathrm{L} \mathrm{Cd}, 5.1 \mu \mathrm{g} / \mathrm{L}$ $\mathrm{Pb})$, and high at the control location $(9.2 \mu \mathrm{g} / \mathrm{L} \mathrm{Cd}$ and $11.5 \mu \mathrm{g} / \mathrm{L}$ of $\mathrm{Pb})$. Relationships were observed between heavy metals, salinity and $\mathrm{pH}$ levels. Results suggest water treated by the facility does not pose heavy metal contamination risks to the Lewes Rehoboth Canal. Further studies are warranted to seek heavy metal sources at the control point, farthest from the waste water treatment facility.
\end{abstract}

\section{Keywords}

Heavy Metals, Cadmium, Lead, Receiving Waters Impacts, Water Quality Monitoring and Assessment

\section{Introduction}

Water is the foundation of life on Earth [1], and there is only one water supply, when taking the hydrologic cycle into account [2]. Studies on road dust sediment (RDS), report its propensity to be infused with heavy metals from wet and dry atmospheric deposition [3] [4] [5]. RDS has been considered as a potential runoff contributor to heavy metals in the aquatic ecosystems [6]. In this study, a waste water treatment plant and the surrounding receiving waters of a tidal can$\mathrm{al} /$ estuarine system are investigated to check if the elements in the waterway are associated with the treatment facility or are because of RDS and other sources. 
The National Oceanic and Atmospheric Administration (NOAA) monitors levels of heavy metals in the United States waters using mussels and oysters all around the nation's coasts, and comprises these levels in the Mussel Watch Report [7]. According to this report, Delaware has regionally medium levels of cadmium (Cd) and regionally high levels of lead $(\mathrm{Pb})$ [7]. The U.S. Geological Survey [8] and others report that wastewater treatment and industrial facilities are potential sources for heavy metals in aquatic systems [9] [10]. In this study, $\mathrm{Cd}$ and $\mathrm{Pb}$ are monitored because the U.S. Environmental Protection Agency [11] states that $\mathrm{Cd}$ and $\mathrm{Pb}$ can both cause health problems when ingested, as in the case of water, a mobile resource.

The state of Delaware is located on the eastern coast of the United States in the Mid-Atlantic region. The physiographical area is along the Atlantic Coastal Plain, and the Inland Bays in Delaware are three bays located inside of two peninsulas that shield the bays from the ocean directly. The study location was just north of Rehoboth Bay, the northernmost Inland Bay, in the Lewes and Rehoboth Canal, which connects the Delaware Bay to the Rehoboth Bay. The wastewater treatment facility focused in this study, is the Rehoboth Beach Wastewater Treatment Plant located in Rehoboth Beach, Delaware. This facility was originally built in 1935 and was upgraded in 1959 as a primary treatment facility for Rehoboth Beach and nearby areas. In 1987, the facility was upgraded once again to become a secondary treatment facility. Once again in 1994 and 1997, the facility was upgraded to include biological nutrient removal and chemical phosphorus removal, utilizing Ferric Chloride $\left(\mathrm{FeCl}_{3}\right)$ as a flocculent for precipitation (Figure 1) [12]. Through many years of upgrades, the discharge location is still being required to be removed from the Lewes and Rehoboth Canal by 2018 due to high nutrient content, and is being considered to be moved to an ocean discharge instead of the canal [13].

\section{Materials and Methods}

Water quality observations and data collection were performed on and near this water treatment plant. Water samples were collected for heavy metal analyses

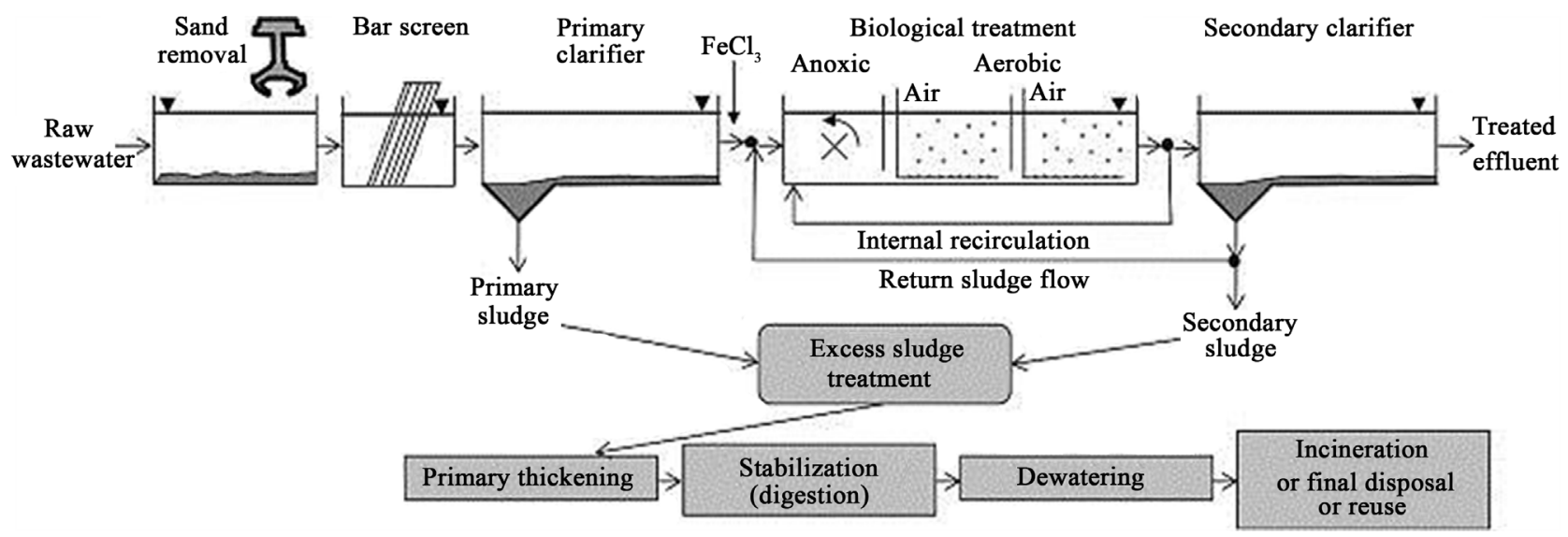

Figure 1. Wastewater treatment process: biological nutrient removal and chemical phosphorus removal [14]. 
from locations at the discharge effluent pipe and sites proximal to the discharge effluent pipe. The possibility of rainfall events in relation to road dust sediment (RDS) was also considered as potential source for heavy metals in the water. So, rainfall events were also examined during the sampling period.

\subsection{Study Locations}

Sample locations were selected as follows: one location directly at the municipal wastewater treatment facility discharge (Location 5), one location seven meters in front of the discharge, where the discharge water is received directly into the brackish tidal canal (Location 2), two more locations, each approximately fifty meters from the effluent on both the northern (Location 1) and southern side (Location 3), and a control location near the end of the canal (Location 4), approximately 800 meters away from the discharge, in proximity to the mouth of the Rehoboth Bay (Figure 2). Water samples were collected weekly in the summer months and bi-weekly in the fall and winter months of 2011, for the period of thirteen months. All samples were analyzed in triplicate to ensure data accuracy.

\subsection{On-Site Water Quality Measurement}

The YSI 556 hand held Multiprobe (YSI Inc., Yellow spring, OH) was utilized in the field for monitoring physical water quality parameters such as temperature, total dissolved solids (TDS), salinity, dissolved oxygen (DO) and pH. The YSI instrument was calibrated monthly, using calibration standards and procedures according to the instructions provided by the manufacturer. Temperature is recorded as the measure of warmth or coldness of the water in degrees C. Total

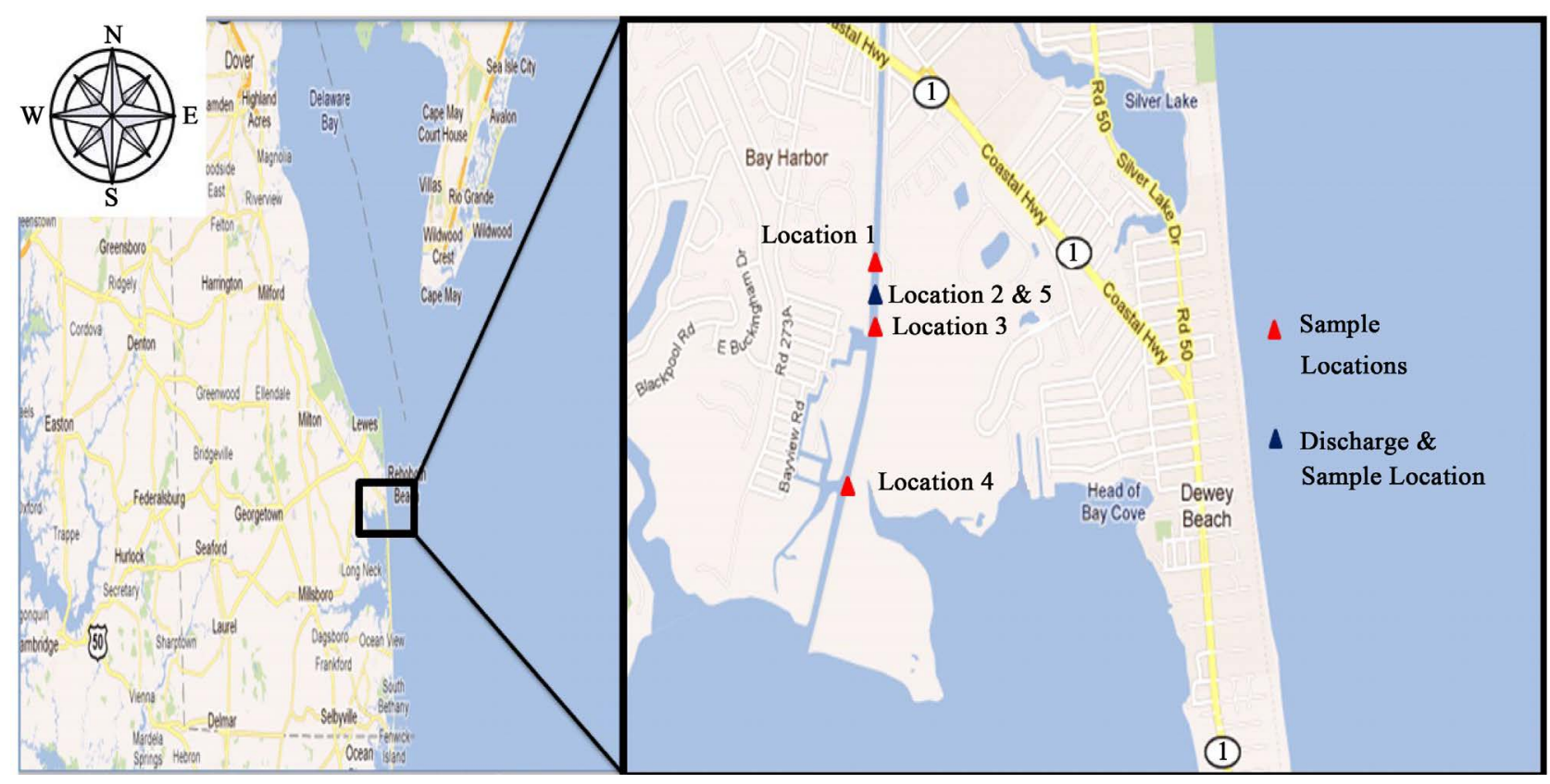

Figure 2. Location 5 is separate because this location is the effluent pipe at the wastewater plant. Location 2 is where Location 5 discharge waters are received into the tidal canal. 
Dissolved Solids (TDS) are a measure of all of the organic and inorganic substances contained in a liquid, either in molecular, ionic, or microscopic soil particles [15]. Whereas, salinity is the measurement of how much salt is present in an aqueous solution [16] and dissolved oxygen (DO) was recorded from the instrument in the form of percent saturation. $\mathrm{pH}$ recorded in this study is a quantification of the molar concentration of the hydrogen ion in solution [17].

\subsection{Water Sampling for Heavy Metal Analysis}

Heavy metal sampling protocols followed EPA Method 1669, to avoid contamination in collection and storage of water samples. The $250 \mathrm{~mL}$ sample containers (Thermo Scientific ${ }^{\mathrm{Tm}}$ Wide-Mouth Short-Profile Amber Glass Jars), which are certified to meet or exceed EPA performance-based standards, were used. Samples were collected by directly submersing bottles into the water and facing upstream of a clean, metal-free kayak, depending upon tidal direction at the time of collection. Sample bottles were inserted into clean storage bags upon collection, and placed in a clean cooler filled with ice for sample storage and transported to the laboratory. In order to minimize sample contamination, the samples were preserved in $0.1 \% \mathrm{HNO}_{3}(\mathrm{v} / \mathrm{v})$ to bring the sample $\mathrm{pH}$ below 2 , and this process was carried out within 12 hours of sample collection.

\subsection{Processing of Water Samples for Heavy Metal Analyses}

Heavy metal samples were prepared and digested using EPA Method 1637, and analyzed in a Perkin Elmer Graphite Furnace Atomic Absorption Spectrophotometer (GFAAS) (AANALYST 600, Shelton, CT) which utilizes single element hollow cathode lamps. A well-mixed, homogenous $20 \mathrm{~mL}$ aliquot of each sample was first checked with a $\mathrm{pH}$ meter to ensure $\mathrm{pH}<2$, then placed into a $50 \mathrm{~mL}$ Fisherbrand $^{\text {tw }}$ graduated conical-bottom tubes. Aliquots were heated in a water bath at approximately $85^{\circ} \mathrm{C}$, and caution was exercised to keep samples covered, maintaining sample integrity, at the same time providing for evaporation. The transpired aliquots were heated until an approximate volume of $2 \mathrm{~mL}$ was left in the tube. Samples were then cooled, and water (Fisher Scientific UltraPure ${ }^{\mathrm{tw}}$ ) was added to bring the sample volume to $10 \mathrm{~mL}, \mathrm{pH}$ was then tested to ensure $\mathrm{pH}$ remained less than 2 . Tubes were then capped and stored overnight to allow any undissolved materials to settle. Before analysis the GFAAS was calibrated using standards specifically for each heavy metal. Stock standards in $1 \%$ nitric acid containing $1000 \mathrm{mg} / \mathrm{L}$ of the heavy metals (cadmium, lead and arsenic) were used (Perkin Elmer, Shelton, CT). The stock was diluted with High Performance Liquid Chromatography (HPLC) grade water, in order to get a final standard concentration of $100 \mu \mathrm{g} / \mathrm{L}$. Matrix modifier prepared with palladium (cadmium) and ammonium hydroxide (lead) was used during the analysis to reduce background noise. The auto sampler (AAS 800) automatically dilutes the stock (100 $\mu \mathrm{g} / \mathrm{L})$ solution to $10,20,30,40$, up to $100 \mu \mathrm{g} / \mathrm{L}$ standard concentrations. For analysis a straight line passing through 0 with a correlation value of greater than 0.95 was considered. The GFAAS was managed and operated by Winlab 32 
software and the atomization program for each metal was used as detailed by Perkin Elmer.

\subsection{Statistical Analysis}

Microsoft Excel (2010) was used to calculate mean, median, and standard deviation, figures and tables were prepared using Microsoft Excel (2010, Redmond, Washington). Reviews of heavy metal data in relation to one another were analyzed using the two-sided t-test. Multivariate analysis was performed on the heavy metal and the physical water quality data to observe the relationships between these variables. Before performing the analysis, the raw data from heavy metals and water quality were normalized and Principal Component Analysis (PCA) was performed using PRIMER 6 program (Primer-E Ltd, Plymouth, UK). Significant environmental variables which had influenced the water quality of the study sites were also identified using PCA.

\section{Results and Discussion}

\subsection{Physical Water Quality}

Field monitoring results included temperature, dissolved oxygen, $\mathrm{pH}$, salinity, and total dissolved solids for the months June 2011 through August 2012. Temperature displayed expected temporal trends that indicate changes in season. The mean temperature in summer 2011 was $27.5^{\circ} \mathrm{C}$, while it was $7.9^{\circ} \mathrm{C}$ in winter 2011. An exception to seasonal variation was recorded at location 5 (waste water discharge location), where temperatures consistently remained somewhat higher than the other locations $\left(10.73^{\circ} \mathrm{C}\right.$ in winter 2011). Dissolved oxygen of a healthy aquatic ecosystem in this temperature range can be sustained at anywhere from 60 - 120 percent saturation [18].

The locations all hovered below the $60^{\text {th }}$ percentile in the summer months, where high algal production can cause somewhat eutrophic conditions [17]. More than half of the sampling distributions of all locations were well within the healthy TDS limits and with levels almost zero at the discharge location. While other locations had higher means ranging from 22.25 - $28.04 \mathrm{~g} / \mathrm{L}$ (Figure 3), which may be because of the normal mixing in the water column. Total Dissolved Solids are considered as secondary drinking water contaminants, a non-mandatory guideline to help manage aesthetic drinking water quality by the USEPA, and as such, the limits do not apply to the brackish water found in this canal. Salinity levels at the wastewater discharge location are found to be 0 ppt. All other location means are between 21.80 - $27.71 \mathrm{ppt}$ (Figure 4), seawater has approximately 30 - 40 ppt [16]. This estuary is below these levels due to freshwater input, and these waters can be classified as brackish. Healthy $\mathrm{pH}$ levels for an aquatic ecosystem are between 6 and 9 [19]. All locations had pH levels within this range (Table 1), although the numbers get closer to 8 in the winter months, and stay closer to 6.5 in the summer months with increased land use activities in the area (Table 1). 


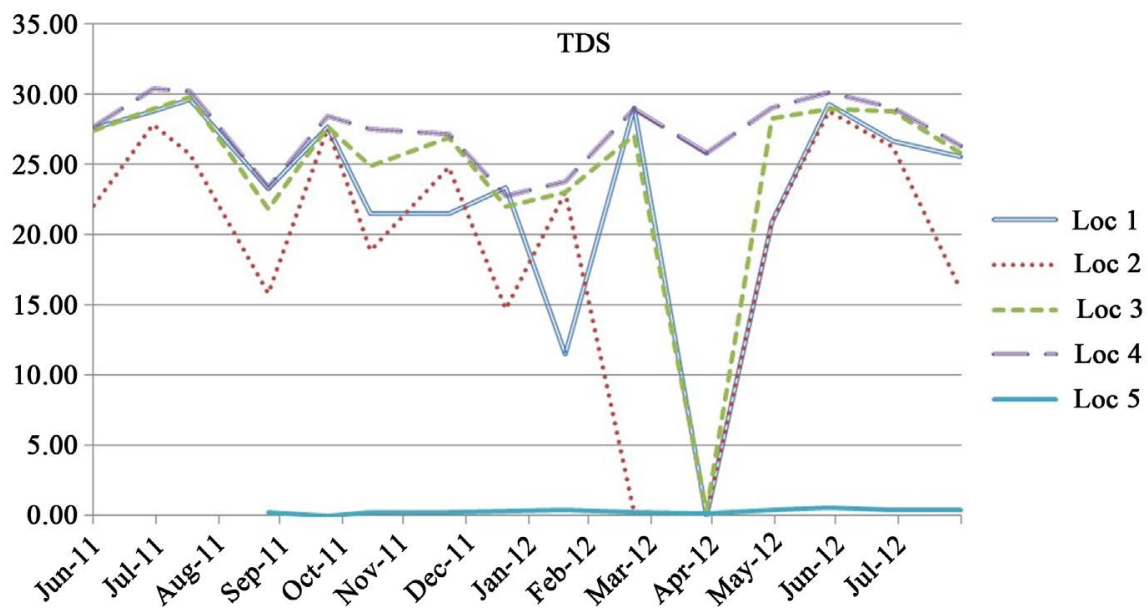

Figure 3. Concentrations of total dissolved solids in $\mathrm{g} / \mathrm{L}$ at study locations from June 2011 to August 2012.

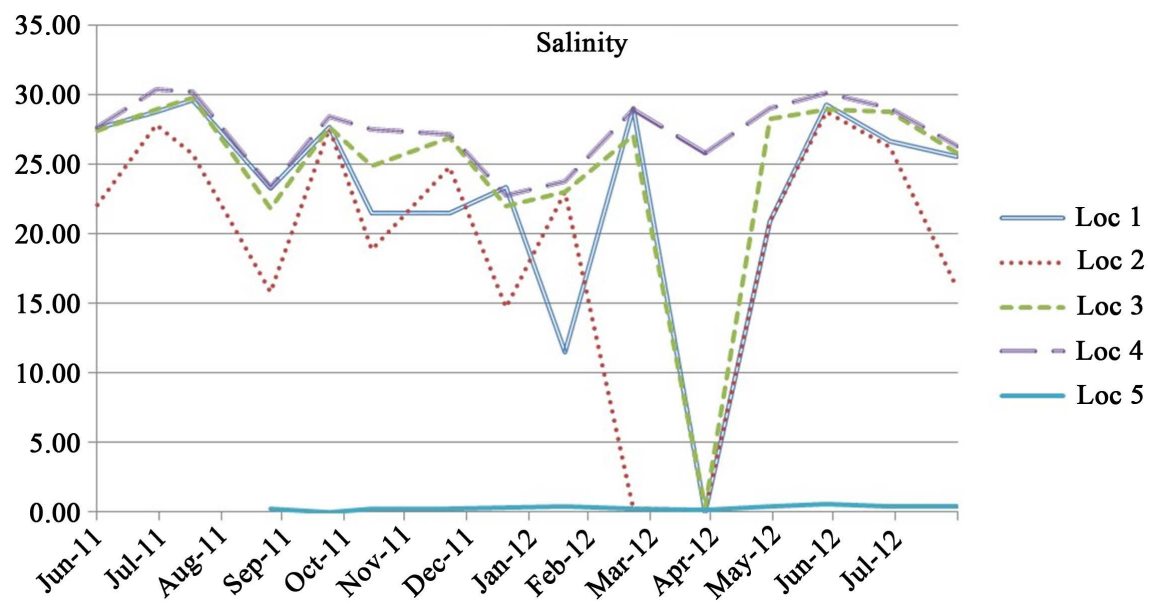

Figure 4. Concentrations of salinity in $\mathrm{g} / \mathrm{L}$ at study locations from June 2011 to August 2012.

Table 1. pH of study locations.

\begin{tabular}{cccccc}
\hline & Location 1 & Location 2 & Location 3 & Location 4 & Location 5 \\
\hline Mean & 7.31 & 7.34 & 7.45 & 7.56 & 7.5 \\
S.D. & 0.388 & 0.362 & 0.385 & 0.351 & 0.400
\end{tabular}

Principal Component Analysis (PCA) was performed to study relationships between the variables. PCA analysis identifies that PC1 and PC2 axes have captured about $81 \%$ of the variation in the data. PCA results show that clear differences can be observed in the study months (Figure 5(a)). Samples collected during summer are high in salinity and total dissolved solids (TDS) which is quite expected because of increased water use activities, while some of the winter samples had high $\mathrm{pH}$ levels.

PCA plot of the water quality for the study years 2011 and 2012 (Figure 5(b)) shows that water samples monitored during these years were not much different. But the winter samples from 2012, belonging to locations 3 and 4 had higher $\mathrm{pH}$ 


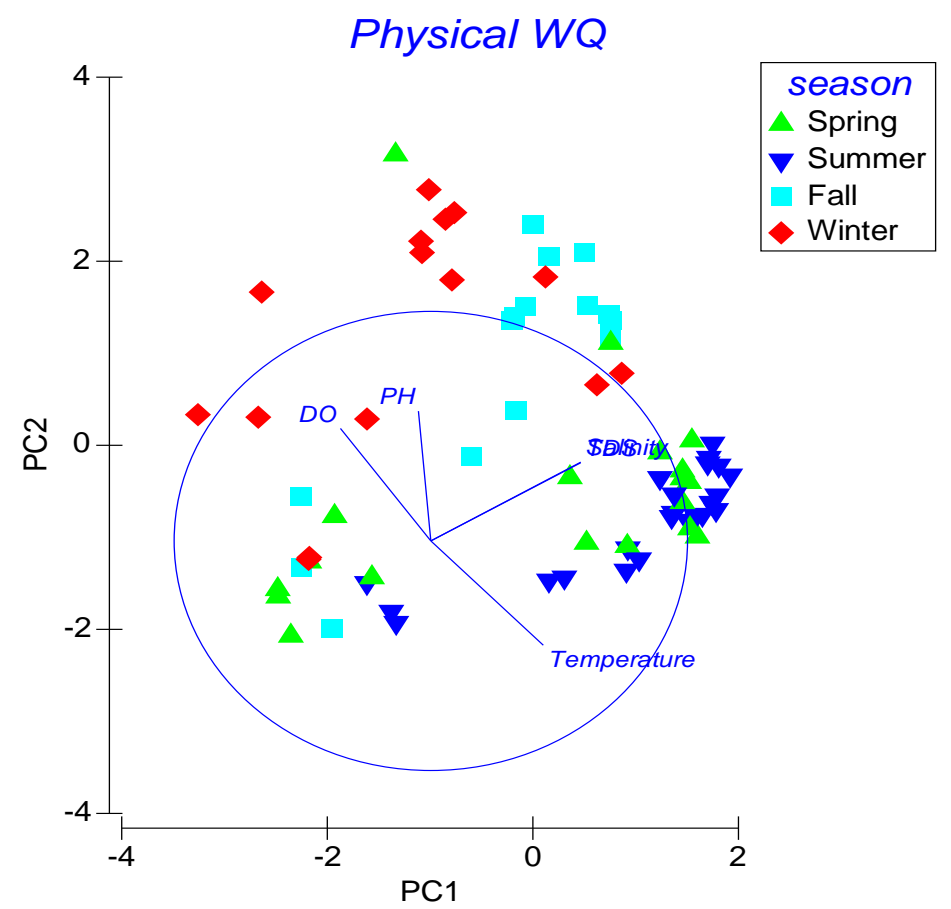

(a)

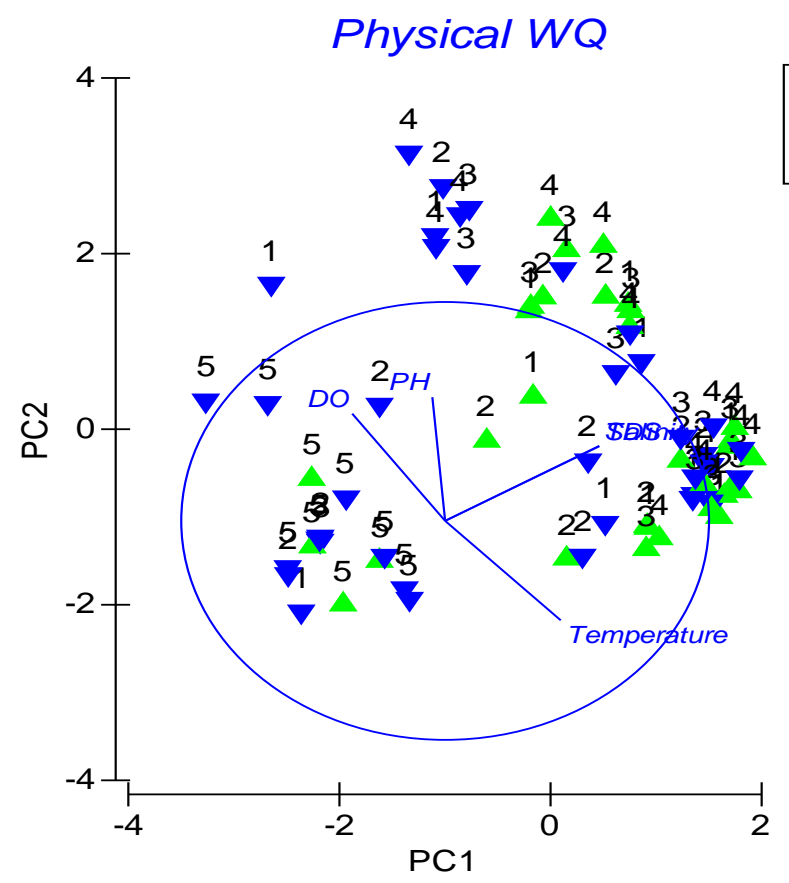

(b)

Figure 5. (a) PCA analysis of physical water quality parameters in relation to the study seasons, each point represents water samples analyzed in the study; (b) PCA analysis of physical water quality parameters for the study years 2011 and 2012, locations of the samples analyzed are shown in this biplot.

values. There are some differences in the study locations and site 5 clearly stands apart from other locations. Site 5 is the location where the water is streaming directly from the present effluent pipe on this waste water treatment site. 


\subsection{Heavy Metals}

Two-sided t-test was performed to find if the heavy metal concentrations at the study locations are statistically different from each other or not. The null hypothesis (Ho) generated for this test is: There are no differences in the levels of metals, $\mathrm{Cd}$ and $\mathrm{Pb}$, at the study locations. The null hypothesis was rejected as significant differences $(p<0.05)$ in the heavy metal concentrations were observed at all study locations with respect to the point source (Location 5$)$ as shown in Table 2, with the exception of $\mathrm{Pb}$ at the locations $2(p=0.14)$ and $3(p$ $=0.07)$. Screening levels obtained from Delaware Department of Natural Resources and Environmental Control (DNREC), were used to determine the levels of contamination of pollutants of concern in a risk assessment process. For the purpose of this study, they are termed background values. These numbers came from the EPA Region III Biological Technical Assistance Group Screening Benchmarks. These are values which relate to the levels of $\mathrm{Cd}$ and $\mathrm{Pb}$ expected to be found in the estuary [20], and the values were compared to the mean levels of metals actually found in this study (Table 3).

For Cd, the EPA Ambient Water Quality Criteria advises $7.9 \mu \mathrm{g} / \mathrm{L}$ as standards for aquatic ecosystem health considering continual exposure, meaning exposure over four days at this level would be severe enough to cause chronic effects at the population level [21]. This level was exceeded at all locations, with the exception of Location 5, which is the direct mouth of the waste water plant discharge and has a mean Cd level of $1.3 \mu \mathrm{g} / \mathrm{L}$. In saline aquatic ecosystems, the chronic critical level of Ambient Water Quality Criteria for $\mathrm{Pb}$ is $5.6 \mu \mathrm{g} / \mathrm{L}$, which, like $\mathrm{Cd}$, is

Table 2. T-test results ( $p$-values $\leq 0.05$ significant) for metal levels between locations.

\begin{tabular}{ccc}
\hline Comparison & $\mathrm{Pb}$ & $\mathrm{Cd}$ \\
\hline Location 1 vs.2 & 0.57 & 0.52 \\
Location 1 vs.3 & 0.5 & 0.87 \\
Location 1 vs.4 & 0.41 & 0.84 \\
Location 1 vs.5 & 0.02 & 0.01 \\
Location 2 vs.3 & 0.99 & 0.6 \\
Location 2 vs.4 & 0.21 & 0.37 \\
Location 2 vs.5 & 0.14 & 0.04 \\
Location 3 vs.4 & 0.16 & 0.69 \\
Location 3 vs.5 & 0.07 & 0.01 \\
Location 4 vs.5 & 0.01 & 0 \\
\hline
\end{tabular}

Table 3. Levels of metals and background (B.G.) values ( $\mu \mathrm{g} / \mathrm{L})[21]$.

\begin{tabular}{cccccccc}
\hline & $\begin{array}{c}\text { Location } \\
\mathbf{1}\end{array}$ & $\begin{array}{c}\text { Location } \\
\mathbf{2}\end{array}$ & $\begin{array}{c}\text { Location } \\
\mathbf{3}\end{array}$ & $\begin{array}{c}\text { Location } \\
\mathbf{4}\end{array}$ & $\begin{array}{c}\text { Location } \\
\mathbf{5}\end{array}$ & $\begin{array}{c}\text { Freshwater } \\
\text { B.G. }\end{array}$ & $\begin{array}{c}\text { Marine } \\
\text { B.G. }\end{array}$ \\
\hline $\mathrm{Pb}$ & 9.4 & 7.9 & 7.8 & 11.5 & 5.1 & 2.5 & 8.1 \\
$\mathrm{Cd}$ & 8.4 & 6.1 & 7.8 & 9.2 & 1.3 & 0.3 & 0.1 \\
\hline
\end{tabular}


not to be exceeded more than four days in an average of once every 3 years [22]. All locations continually had $\mathrm{Pb}$ levels above the recommended Ambient Water Quality Criteria concentration; with the exception of location 5 which had a mean $\mathrm{Pb}$ of $5.1 \mu \mathrm{g} / \mathrm{L}$. This shows that this effluent pipeline is not a source for lead and cadmium contamination in this water system. Background levels, as described above, for both freshwater and marine water systems are given in $\mathrm{Ta}$ ble 3 due to the brackish nature of the study area.

\subsection{Correlations between Water Quality Parameters and Heavy Metal Levels}

As PCA analysis revealed that water samples had higher concentrations of salinity, TDS and $\mathrm{pH}$, correlation studies were performed to check how these parameters will influence the levels of cadmium and lead in the water. Pearson correlation coefficient $(\mathrm{R})$ was calculated and presented in Table 4. Ho: There is no difference between levels of metals and salinity in solution. When $\mathrm{Pb}$ levels were tested in relation to salinity, a positive correlation of $(\mathrm{R}=0.32)$ was observed for locations 1 and 2. There were no significant correlations found for the other study sites. Whereas, inverse relationships were observed for Cd levels and water salinity levels. These relationships were high in the study location $1(-0.80)$, location $5(-0.50)$ and location $3(-0.46)$. Brackish waters of this estuary have shown a proclivity towards diverse and reactive systems which demonstrate levels of heavy metals, apart from sodium chloride concentrations, as found in other studies [23] [24]. Interestingly, strong relationships between the heavy metal levels and the $\mathrm{pH}$ of water samples were not observed. It was also hypothesized there would be no difference between levels of metals and $\mathrm{pH}$ in solution. Surprisingly the correlations for $\mathrm{Pb}(\mathrm{R}=0.38)$ and $\mathrm{Cd}(\mathrm{R}=0.37)$ at location 4 remain almost the same with the water $\mathrm{pH}$. Location 2 has higher positive relations for water $\mathrm{pH}$ and Cd levels $(\mathrm{R}=0.48)$.

Although, there are no strong correlations for $\mathrm{pH}$ and heavy metals in this study, previous reports indicate the effect of $\mathrm{pH}$ on the adsorption and desorption of heavy metals in water systems [25] [26].

\subsection{Precipitation Effects on Heavy Metals}

Studies report runoff from roadside dust is one of the major contributors of

Table 4. Correlation coefficients between salinity and pH levels of metals.

\begin{tabular}{ccccc}
\hline \multirow{2}{*}{ Sites } & \multicolumn{2}{c}{ Salinity vs. Metals } & \multicolumn{2}{c}{$\mathrm{pH}$ vs. Metals } \\
\cline { 2 - 4 } & $\mathrm{Pb}$ & $\mathrm{Cd}$ & $\mathrm{Pb}$ & $\mathrm{Cd}$ \\
\hline Location 1 & 0.324 & -0.805 & 0.046 & -0.270 \\
Location 2 & 0.327 & -0.203 & 0.017 & 0.480 \\
Location 3 & -0.224 & -0.462 & -0.011 & 0.186 \\
Location 4 & 0.013 & -0.508 & 0.385 & 0.376 \\
Location 5 & 0.099 & -0.189 & -0.274 & -0.319 \\
\hline
\end{tabular}


metals as potential pollutants in the aquatic systems [4] [5]. Examining the levels of $\mathrm{Cd}$ and $\mathrm{Pb}$ at the study locations in relation to rainfall events has been detailed in Figure 6(a) and Figure 6(b) (Ho: There is no difference between levels of metals and precipitation levels). Direct relationships between rainfall and lead have been identified in locations $1(\mathrm{R}=0.34)$ and $3(\mathrm{R}=0.31)$. This shows there is a potential for these locations (situated directly at the north and south of the discharge) to have been affected by the precipitation entering the canal by way of runoff. No correlations were found for $\mathrm{Cd}$ in relation to rainfall events in this study.

Lower levels of $\mathrm{Pb}$ are seen in the data when rainfall levels are higher. The same result is found for $\mathrm{Cd}$, but it was more pronounced for Cd (Figure 6(a) and Figure 6(b)). This is thought to be attributed to road dust sediment adsorption of metal ions in colloidal particles. Adsorption of the metal ions makes them less available in solution [27], as shown by the graph data above.

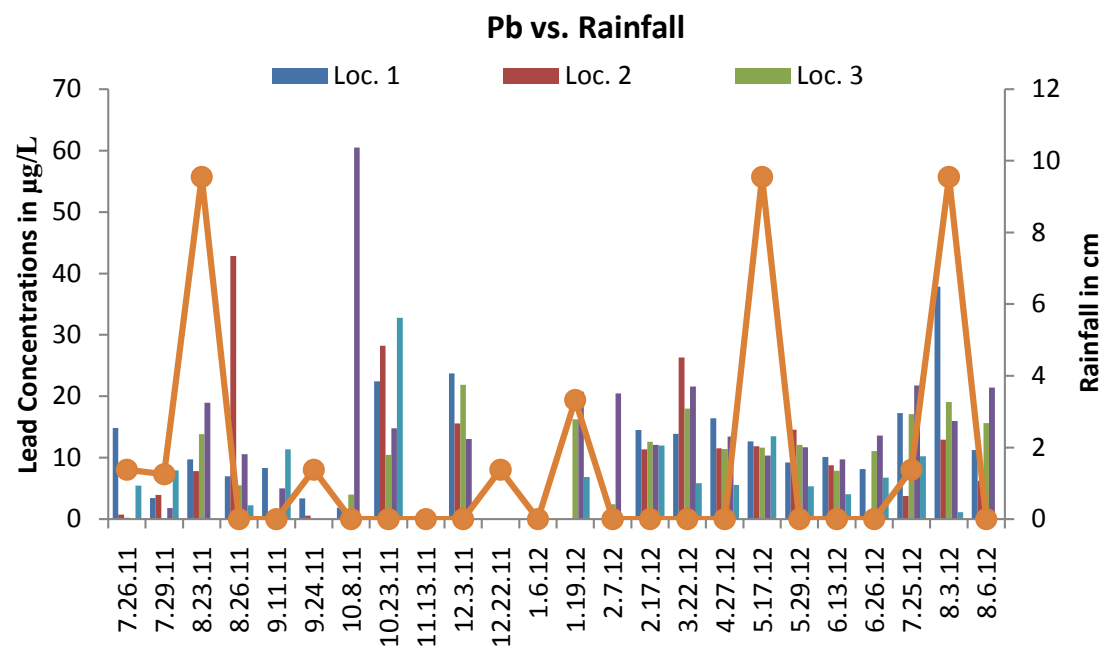

(a)

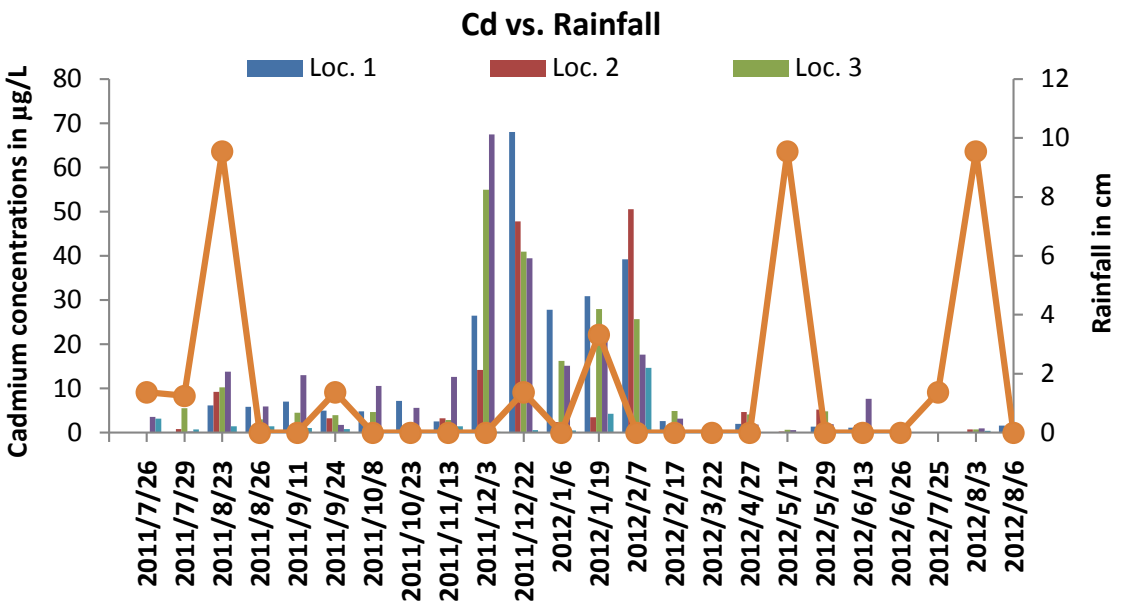

(b)

Figure 6. (a) Effects of rainfall trends on concentrations of lead $(\mathrm{Pb})$ in water samples at the study locations; (b) Effects of rainfall trends on concentrations of cadmium (Cd) in water samples at the study locations. 
Therefore, it is observed the levels of heavy metals are highly dependent on the physical water quality and precipitation effects.

Salinity vs. heavy metals. Salinity recordings in relation to the heavy metal levels displayed an inverse correlation for locations 1, 3 and 4, where locations 1 and 3 are directly north and south of the discharge and location 4 is the control location (near the mouth of the Rehoboth Bay). These locations are further away from the discharge than the other locations ( 2 and 5), which may depict a relationship to the more natural ecosystem surrounding these locations, and the suspended salts in the waters may be capable of bonding with the positively charged metals ions suspended in the surrounding waters [27]. The relationship between salinity and metals is greater at location 1, which may be due to this location being situated spatially closest to the motor vehicle traffic bridge on Route 1 , which crosses the tidal canal for motorists, and is subject to winter salting. $\mathrm{Pb}$ ions are denser than $\mathrm{Cd}$ ions, and as such, are more susceptible to sinking into the benthos more quickly. This explains why levels of $\mathrm{Pb}$ in relation to salinity are not shown to be variables which affect one another in this study.

$p H$ vs. heavy metals. With regards to $\mathrm{pH}, \mathrm{Cd}$ levels are shown to reflect a small positive correlation in locations 2 and 4 (receiving waters of the canal and control locations, respectively). Levels of $\mathrm{Pb}$ in relation to $\mathrm{pH}$ also have small positive correlation in location 4 (control location). The control location is farthest from the discharge location, exhibits a small positive correlation with both metals. This shows that when $\mathrm{pH}$ increases, so also do levels of metals, as it becomes more difficult for the metals ions to find others to bond with, because increased $\mathrm{H}^{+}$ions compete with the positively charged heavy metal ions for colloidal partners in solution [27].

Rainfall vs. metals. Levels of metals in relation to rainfall events were also studied to consider the potential for roadside dust sediment (RDS) to exist with metals already adsorbed on land, as well as the potential for RDS to form colloids with metals in suspension once the dust reaches the aquatic ecosystem. Only locations 1 and 3 were found to show slightly positive correlations with rainfall events and levels of metals in this tidal canal. This is thought to be due to the ability of the banks of this canal to stabilize road dust sediment prior to runoff entering the waterway. The banks of this canal act as a strong catchment area, even with the nearby roadway crossing the canal as a major motor vehicle traffic route in this area.

\section{Conclusion and Future Suggestions}

The USEPA and NOAA departments in Delaware helped in identifying the wastewater treatment facility as a potential contaminant source of heavy metals to this local aquatic environment. Sampling and testing methods established by the EPA have been used to determine the aquatic health of the Lewes and Rehoboth Canal. The findings show the wastewater treatment facility is not causing the deposition of heavy metals into the water system. Levels of heavy metals were consistently below the recommended levels at the wastewater treatment 
plant discharge (Location 5). Heavy metals concentrations were highest at the control location (Location 4) which is located south of the discharge, and nearest to the mouth of the Rehoboth Bay. The mean $\mathrm{Cd}$ and $\mathrm{Pb}$ levels for locations 1 through 4 are successively well above $7.9 \mu \mathrm{g} / \mathrm{L}$ and $5.6 \mu \mathrm{g} / \mathrm{L}$ chronic exposure standards set forth by the EPA Ambient Water Quality Criteria. Location 5 is the only location having a mean data set less than the standard limits for both $\mathrm{Cd}$ and $\mathrm{Pb}$. Similarly, background levels for $\mathrm{Cd}$ exceeded at all locations, while background values for $\mathrm{Pb}$ exceeded at all locations except for locations 2 and 5 . There are unexpected levels of heavy metals within the aquatic ecosystem of the Lewes and Rehoboth tidal canal. The data shows contamination risks for future research opportunities in regards to further examination of heavy metals in this estuary. Long term monitoring of the area with multiple testing sites will warrant strong data collection and help resource managers to identify or track the source(s) of contamination in the Lewes and Rehoboth Canal.

\section{Acknowledgements}

This project is funded by USDA-NIFA, DWRC, NSF-EPSCoR, NSF-SMILE programs. A special thanks to Dr. Venugopal Kalavacharla, for devoting invaluable time and energy in completion and support of this research. We would like to thank Dr. Thomas Smolinski, Project Coordinator of the NSF SMILE Program and Ms. Maria Pautler of UD DWRC for their continuous support and assistance. We are very grateful to the Graduate Student, Ken Hannum for his assistance with this research. Lastly, we would like to thank Dr. Stacy Smith for maintaining a much-appreciated stellar and steady well of kind help.

\section{Conflict}

Authors of this manuscript have no conflict of interests to declare.

\section{References}

[1] Rush, E.C. (2013) Water: Neglected, Unappreciated and under Researched. European Journal of Clinical Nutrition, 67, 492-495. https://doi.org/10.1038/ejcn.2013.11

[2] Trenberth, K.E. and Fasullo, J.T. (2013) Regional Energy and Water Cycles: Transports from Ocean to Land. Journal of Climate, 20, 7837-7851. https://doi.org/10.1175/JCLI-D-13-00008.1

[3] Ahmed, F., Bibi, M.H. and Ishiga, H. (2007) Environmental Assessment of Dhaka City (Bangladesh) Based on Trace Metal Contents in Road Dusts. Environmental Geology, 51, 975-985. https://doi.org/10.1007/s00254-006-0367-1

[4] Shi, G., Chen, Z., Xu, S., Zhang, J., Wang, L., Bi, C. and Teng, J. (2008) Potentially Toxic Metal Contamination of Urban Soils and Roadside Dust in Shanghai, China. Environmental Pollution, 156, 251-260. https://doi.org/10.1016/j.envpol.2008.02.027

[5] Duong, T.T.T. and Lee, B.K. (2011) Determining Contamination Level of Heavy Metals in Road Dust from Busy Traffic Areas with Different Characteristics. Journal of Environmental Management, 92, 554-562. https://doi.org/10.1016/j.jenvman.2010.09.010

[6] Sutherland, R.A. and Tolosa, C.A. (2001) Multi-Element Analysis of Road-Depo- 
sited Sediment in an Urban Drainage Basin, Honolulu, Hawaii. Environmental Pollution, 3, 483-495.

[7] Kimbrough, K.L., Johnson, W.E., Lauenstein, G.G., Christensen, J.D. and Apeti, D.A. (2008) An Assessment of Two Decades of Contaminant Monitoring in the Nation's Coastal Zone. Silver Spring, MD, NOAA Technical Memorandum NOS NCCOS 74. 69.

[8] U.S. Geological Survey (USGS) (2016) Wastewater Treatment Water Use. https://water.usgs.gov/edu/wuww.html

[9] Garbarino, J.R., Hayes, H.C., Roth, D.A., Antweiler, R.C., Brinton, T.I. and Taylor, H.E. (1995) Contaminants in the Mississippi River. U.S. Geological Survey Circular 1133. Reston, VA.

[10] Muchie, M. and Akpor, O.B. (2010) Remediation of Heavy Metals in Drinking Water and Wastewater Treatment Systems: Processes and Applications. International Journal of the Physical Sciences, 12, 1807-1817.

[11] USEPA (2016) Groundwater and Drinking Water. Table of Regulated Drinking Water Contaminants.

https://www.epa.gov/ground-water-and-drinking-water/table-regulated-drinking-w ater-contaminants

[12] Stenger, R. (2008) City of Rehoboth Beach Wastewater Treatment Facilities: A Historical Narrative.

http://www.cityofrehoboth.com/sites/default/files/Bob_Stenger_CityWastewaterDe partmentPresentation06-16-08_1.pdf

[13] Globetti, M. (2015) DNREC Moves City of Rehoboth Beach Wastewater Disposal Financing Forward and Agrees to New Discharge Removal Deadline. Delaware Department of Environmental Resources and Environmental Control.

[14] Margot, J., Rossi, L., Barry, D.A. and Holliger, C. (2015) A Review of the Fate of Micropollutants in Wastewater Treatment Plants. WIREs Water, 2, 457-487. https://doi.org/10.1002/wat2.1090

[15] Pizzi, N.G. (2010) Water Treatment: Principles and Practices of Water Supply Operations Series. 4th Edition, American Water Works Association.

[16] Singh, V.P., Singh, P. and Haritashya, U.K. (2011) Encyclopedia of Snow, Ice and Glaciers. Springer Science and Business Media, The Netherlands.

[17] Manahan, S.E. (2011) Water Chemistry: Green Science and Technology of Nature's Most Renewable Resource. CRC Press, Taylor \& Francis Group, Boca Raton.

[18] West Virginia Department of Environmental Protection (WVDEP) (2017) Percent Saturation of Dissolved Oxygen. Information adapted from: Water, Water Everywhere: Water Quality Factors Reference Unit, HACH Inc. http://www.dep.wv.gov/WWE/getinvolved/sos/Documents/SOSKit/DOSaturation.p df

[19] Weiner, E.R. (2013) Applications of Environmental Chemistry. Applications of Environmental Aquatic Chemistry: A Practical Guide. 3rd Edition, CRC Press, Taylor \& Francis Group, Boca Raton.

[20] DNREC (2016) SIRS Screening Level Table. Division of Waste and Hazardous Substances. http://www.dnrec.delaware.gov/dwhs/sirb

[21] United States Environmental Protection Agency, Office of Water (2016) March 2016 Aquatic Life Ambient Water Quality Criteria for Cadmium. USEPA Report, Washington DC.

[22] United States Environmental Protection Agency, Office of Water (1985) Regulations and Standards, Criteria and Standards Division. Ambient Water Criteria for 
Lead-1984. USEPA Report, Washington DC.

[23] Scoullos, M. and Pavlidou, A.S. (2003) Determination of the Lability Characteristics of Lead, Cadmium and Zinc in a Polluted Mediterranean Brackish-Marine Interface System. Water, Air and Soil Pollution, 147, 203-227. https://doi.org/10.1023/A:1024524932163

[24] Karbassi, A.R., Heidari, M., Vaezi, A.R., Valikhani Samani, A.R., Fakhraee, M. and Heidari, F. (2014) Effect of $\mathrm{pH}$ and Salinity on Flocculation Process of Heavy Metals during Mixing of Aras River Water with Caspian Sea Water. Environmental Earth Science, 72, 457-465. https://doi.org/10.1007/s12665-013-2965-Z

[25] Abollino, O., Aceto, M., Malandrino, M., Sarzanini, C. and Mentasti, E. (2003) Adsorption of Heavy Metals on Na-Montmorillonite. Effect of $\mathrm{pH}$ and Organic Substances. Water Research, 37, 1619-1627. https://doi.org/10.1016/S0043-1354(02)00524-9

[26] Li, Y., Wang, J.-D., Wang, X.-J. and Wang, J.-F. (2012) Adsorption-Desorption of $\mathrm{Cd}(\mathrm{II})$ and $\mathrm{Pb}(\mathrm{II})$ on Ca-Montmorillonite. Industrial and Engineering Chemical Research, 51, 6520-6528. https://doi.org/10.1021/ie203063s

[27] Baird, C. and Cann, M. (2008) Environmental Chemistry. 4th Edition, W.H. Freeman and Company, New York.

Submit or recommend next manuscript to SCIRP and we will provide best service for you:

Accepting pre-submission inquiries through Email, Facebook, LinkedIn, Twitter, etc. A wide selection of journals (inclusive of 9 subjects, more than 200 journals)

Providing 24-hour high-quality service

User-friendly online submission system

Fair and swift peer-review system

Efficient typesetting and proofreading procedure

Display of the result of downloads and visits, as well as the number of cited articles

Maximum dissemination of your research work

Submit your manuscript at: http://papersubmission.scirp.org/

Or contact jwarp@scirp.org 